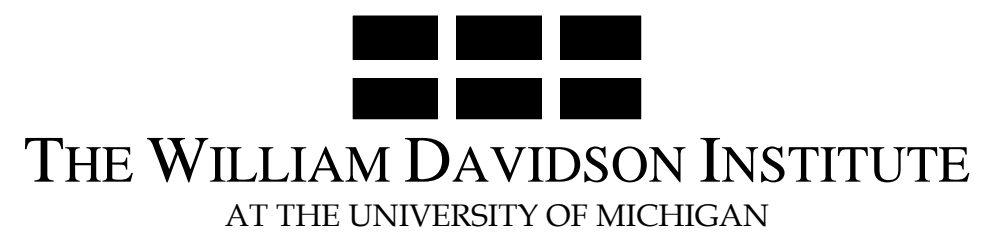

AT THE UNIVERSITY OF MICHIGAN

\title{
Establishing Data Collection Procedures Equivalence in International Business Research
}

By: Agnieszka Chidlow \& Pervez N. Ghauri

William Davidson Institute Working Paper Number 1013

March 2011 


\title{
Establishing Data Collection Procedures Equivalence in International Business Research.
}

\author{
Agnieszka Chidlow $\cdot$ Pervez N. Ghauri
}

\begin{abstract}
:
Following a number of earlier studies on data equivalence in cross-cultural international business research, this article uses a content analysis of articles published in four leading international business journals from 2000 to 2009 , to uncover the equivalence in current state of data collection procedures used by researchers in mail surveys.
\end{abstract}

The results show that, despite repeated calls and the existence of a well established theoretical framework for mail survey data collection by Don Dillman $(1978,1999)$, international business scholars have not been inspired to adopt and report the data collection procedures adequately in their work. We hope this work will draw due attention to the aspect in international business research.

Keywords: International business research $\cdot$ Mail survey $\cdot$ Data collection procedure $\cdot$ Equivalence and Content analysis.

JEL Codes: A30, B41, M16

Associate Professor A. Chidlow, PhD

Centre for International Business and Innovation, Manchester Metropolitan University, Manchester, UK

e-mail: a.chidlow@mmu.ac.uk.

Professor P.N. Ghauri, PhD

Department of Management, King's College London, London, UK 


\section{Introduction}

An increasing interdependence among international companies and economies has led to an unprecedented surge in international trade and investment activities forcing both managers and researcher to seek information and make sense of cross-cultural data. However, undertaking international research based on multi-country surveys has long been acknowledged as a difficult task (Przeworski and Teune, 1966; Berry, 1969; Sekaran, 1983; Nasif et al., 1991; Cavusgil and Das, 1997). While workable solutions have been offered in areas such as; questionnaire development and data anlysis techniques (Jobber et al., 1991; Jobber and Saunders 1988; Harzing, 1997; Brock, 2003; Reynolds et al., 2003), achieving equivalence in data collection procedures and methods still remain to be resolved (Kjeldgaard et al., 2006; Yaprak, 2006; Hult et al., 2008, Piekkari et al., 2009). The data collection procedure equivalence which includes comparability with regards to research instrument equivalence (e.g. face-to-face interviews, mail surveys, etc), the sampling coverage and survey administration procedures (Craig and Douglas, 2000; Hult et al., 2008), if not achieved, threatens the main purpose of conducting cross-cultural research.

By examining six top international business (IB) journals in search of a common research practice, Yang et al., (2006: 216), found that a mail survey questionnaire was "the most popular data collection method" utilised by IB scholars between 1992 - 2003. This finding was consistent with previous studies of Peng et al. (1991) and Adler (1983a). As postal surveys dominate other methods of gathering cross-cultural data, the aim of this work is to investigate "if" and "how" international business scholars report postal survey administration procedures in the last decade and whether or not we can establish an equivalence of data collection procedures in international business research. We believe, and as pointed out by many researchers (Sekaren 1983, Nasif et al 1991 and Hult et al 2008) establishing data collection procedure equivalence is an important step towards achieving overall comparability and equivalence in cross cultural research. Most studies, mentioned above, point out five broad types of concerns; functional equivalence, instrumentation equivalence, data collection method equivalence, sampling design equivalence and data analysis equivalence. Most of these concerns have been addressed by earlier studies (Harris, 2000; Hult et al., 2008; Cavusgil and Das, 1997; Mullen, 1995; Nasif et al., 1991), however, we believe that considering the maturity of our discipline, there is a need to go deeper into the data collection method equivalence issue to see whether the data collection procedures proposed by scholars (e.g. Dillman 1978 and 1999) are followed in cross-cultural research or not. As, the equivalence in data collection procedure is the key to achieving equivalence in the collected data. The study is structured as follows. First, it draws attention to data collection procedure equivalence. Second, it turns to the multiple-contacts for mail surveys proposed by Dillman $(1978,1999)$. Third, it points out at the effectiveness of Dillman's framework, grounded in a social exchange perspective, to 
cross-cultural research. Fourth, it presents the analytical approach that was used to examine data on the mail survey administration procedures employed in 285 studies that were published in four highest ranked international business journals between 2000 and 2009. Fifth, it reports the results in line with the paper's objectives. Finally, it focuses on discussions and implications of the findings for IB research and presents its conclusions.

\section{Data collection procedure equivalence}

By going beyond the borders of one country, doesn't mean that comparative research differs from any other type of social science inquiry with respect to its rigour. Hence, like any other social science analysis, cross-cultural research requires procedures that involve caution in order to yield validity and reliability in more differentiated settings to enable us to ensure generalizability of implications across borders (Hult et al., 2008).

Methodological issues in cross-cultural analysis, with respect to equivalence, have been the subject of investigation for many academics across several disciplines over the past four decades (Przeworski and Teune, 1966; Berry and Dasen, 1974; Green and White, 1976; Adler, 1983; Cavusgil and Das, 1997; Nasif et al., 1991; Sekaran 1981; Herk et al., 2005; Coviello and Jones, 2004; Hult et al., 2008).

Craig and Douglas (2000, p.141) define equivalence as "data that have, as far as possible, the same meaning or interpretation, and the same level of accuracy, precision of measurement, or reliability in all countries and cultures". This implies that "the elements of a research design have the same meaning and can be applied in the same way, in different cultural contexts" (Hult et al., 2008, p. 1027).

The idea of equivalence is supported based on two concepts: "emic" and "etic"1 The aim of an emic approach is to examine a phenomenon with specific concepts used in a particular culture. However, the goal of an etic approach is to study a phenomenon in order to develop a universal law that can identify commonalities and differences across cultures using equivalent concepts, metric or indicators (Peng et al., 1991; Cavusgil and Das, 1997; Schaffer and Riordan, 2003; Ghauri and Gronhang, 2010). The challenge that faces cross-cultural scholars lies in the choice between these two approaches and it is known in the management literature as the etic-emic dilemma (Adler, 1984).

Following the work of Sekaran (1983) in comparative research, in general terms, five forms of equivalence are distinguished: functional equivalence, instrumentation, data collection, sampling design, and data analysis. Other researchers in this field, for example, Adler (1983), Nasif et al. (1991), Peng et al. (1991), Cavusgil and Das (1997), and Hult et al. (2008) have supported the above framework. In brief, the functional equivalence is linked with the roles of objects or 
behaviours in different countries. Instrumentation equivalence takes account of equivalence in translation, concepts and syntax. Data collection equivalence stresses the importance of comparability across cultures with regards to the sources of data, the methods of eliciting data, constructs and questionnaire items. Sampling equivalence consists of such issues as representativeness and matching of samples across cultures. Data analysis equivalence demonstrates whether or not cross-cultural data can be taken, analysed and composed as equivalent to provide comparable and generalizable results.

Following the establishment of the equivalence framework in comparative research, Cavusgil and Das (1997) developed a seven stage methodology model for conducting cross-cultural studies. In their generic model, they address various equivalence issues that have to be accounted for when undertaking cross-cultural research (e.g. conceptual equivalence, functional equivalence). However, in our view, they do not pay much attention to data collection procedure equivalence that can be used, for example, in a postal survey. Hence, building on their work, and mainly focusing on the data collection stage of their model $^{2}$, we hope to demonstrate the importance of data collection procedure equivalence of a mail survey, which is an integral element of data collection equivalence. In our view data collection equivalence is essential for knowledge creation in the field of IB research as it influences the response rate which represents generally accepted proxy for nonresponse error (Figure 1). 
Figure 1. Data Collection Procedure Equivalence in Cross-cultural Research: A Postal Survey.

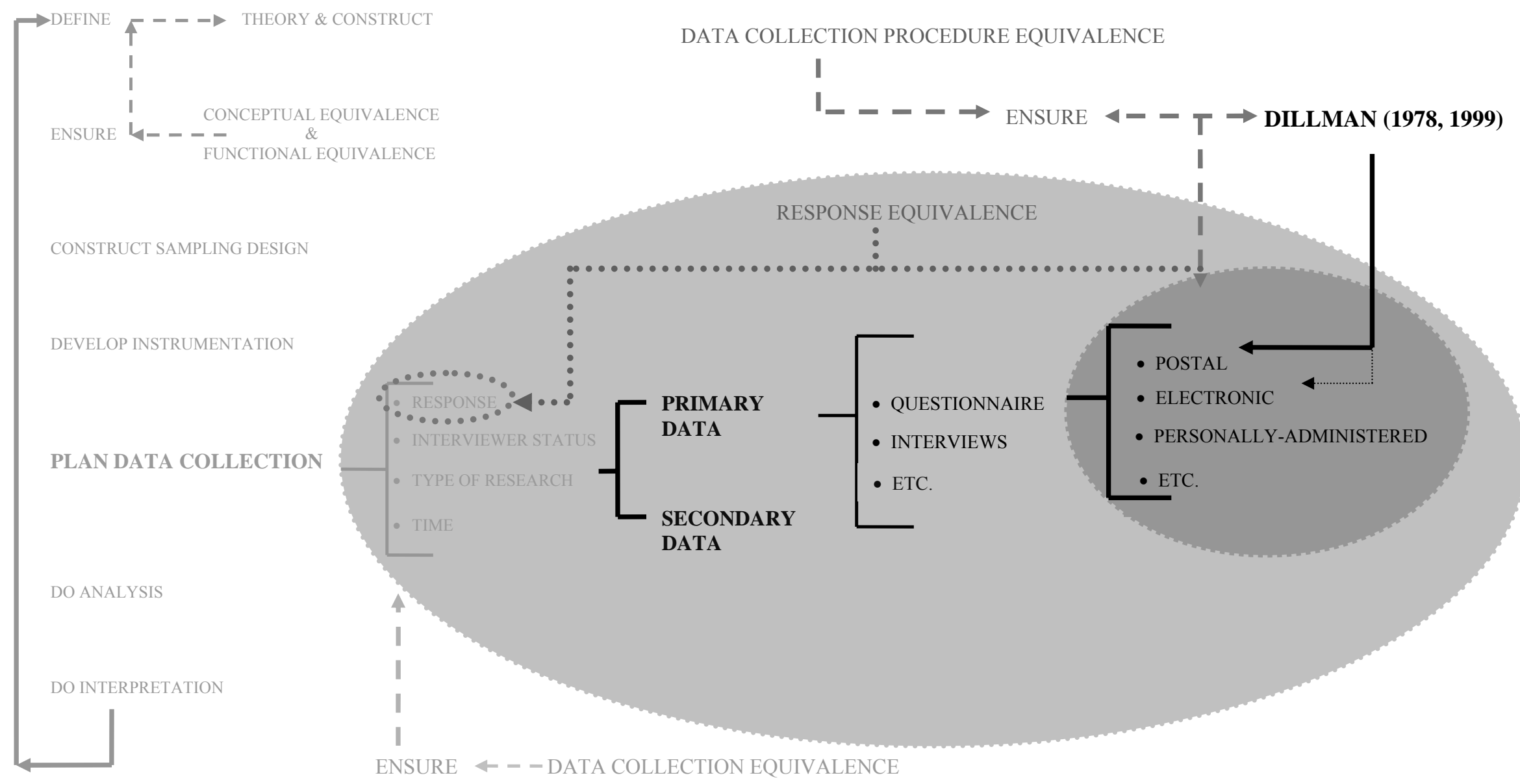

Source: Based on Cavusgil and Das (1997) 
When designing a cross-cultural research a careful attention should be focused, amongst other things, on data collection to ensure comparability across cultures. This is because many countries have noticeably different social systems, literacy rates, and cultural norms and values. Even the country with the same language might use different vocabulary (e.g. Germany/Austria, USA/UK). During the data collection phase, timing of data gathering in different cultures, interviewer status, type of research, and response equivalence are important (Sekaran, 1983; Nasif et al., 1991; Cavusgil and Das, 1997, Herk et al., 2005). Thus, to provide equivalence within the data collection stage, great effort should be made to ensure that data collection in the different research places are as simultaneous as possible, as this enhances the comparability of the data collected. In addition, the researcher should also place emphasis on the status and authority in the data collection process as different cultures have different understanding of power and authority (Hofstede 1980). Further, researchers are encouraged to use a mix-method approach for gathering data to give a static and dynamic picture of research sites. Finally, "response equivalence can be ensured by adopting uniform data collection procedures in all the cultures in which a problem is being investigated" (Sekaran, 1983, p. 63).

As researchers are opened to the use of many techniques in gathering cross-cultural data to warrant data collection equivalence, it is adequate to say that different methods will acquire different data collection procedures. Looking at Figure 1 and focusing on primary data collection methods, mainly those that use a questionnaire as a tool of gathering data, it is critical to say that different administration procedures can be used by researchers depending on the ways the questionnaire is sent out to potential respondents (e.g. a postal vs a personally-administered questionnaire). For example, a researcher chooses to sent out a questionnaire by mail then a comprehensive framework of administration procedures developed by Dillman (1978) could be used to ensure data collection procedure equivalence ${ }^{3}$. As administration procedures are critical to achieve a sufficient response rate, establishing data collection procedure equivalence would enable researchers to establish equivalence in the information collected. This is because the issues of equivalence are linked to stages in the research process, for example, equivalence of administration and equivalence of responses are linked to the phase in the research process where the instrument is developed.

Before we discuss the system of administration procedures (see next section) for mail survey developed by Dillman (1978) that could ensure equivalence in administration and response, we first turn the attention to the sources of biases that could be found in survey methodologies.

When undertaking comparative survey research, scholars face at least four potential sources of bias, any of which can make the results unacceptable. These sources of error contain: sampling error, non-coverage error, measurement error and non-response error (Groves, 1989, 2004; Dillman, 
1991; Weisberg, 2005) ${ }^{4}$. Challenges to employ quality postal surveys require attempts to eliminate, or at least reduce, all four types of error.

Sampling error occurs when a sample of the population rather than the whole population is surveyed. It is the aspect of survey quality examined through inferential statistics applied to sample survey results, from which conclusions about significant differences in the population are achieved. In comparative research, sampling error "should be referenced and standardized with regards to the extent of presence of the underlying statistical assumptions in each culture or country" (Cavusgil and Das, 1997, p.87). Results ought to be presented in terms of comparable statistical terms and estimates (Brock, 2003).

Non-coverage error arises when some members of the population are not covered by the sampling frame and therefore have no possibility of being selected into the sample. It has been proposed (see e.g. Samiee and Jeong 1994) that paying close attention to the sample frame in the countries being studied and ensuring sample selection in cross-cultural research can increase withinsample homogeneity.

Measurement error takes place when the measure obtained fails to reflect the accurate extent to which the subject possesses the attribute being measured. The error may arise due to, for example, flaws in scale design, instrument invalidity and inadequate application of the scale. However, various steps have been proposed in comparative research literature to minimize the measurement error and at the same time to ensure measurement equivalence (Hult et al., 2008).

Non-response error appears from the fact that some of the members of the sample population do not respond to the survey questions. The substantial amount of research on improving mail survey methods has focused on response rates and a generally accepted proxy for non-response error has been established (Heberlein and Baumgatner, 1978; Eichner and Habermehl, 1981; Baruch and Holtom, 2008; Cycota and Harris 2006). This almost singular focus on response rates takes place because high non-response bias has long been considered as the major drawback of postal surveys. Just as important, however, is the awareness fostered by much of the comparative research literature that such studies could be successful if somewhat uniform administration procedures were identified, as equivalence of administration procedures and equivalence of responses are linked during the research process. Maintaining equivalence in data collection procedures might appear straightforward (Hult el al., 2008). However, in spite of the efforts made, the nature of international business research poses threats and often leads to disparities in data collection procedures (Eichner and Habbermelh, 1981). Hence, the establishment of appropriate and comparable survey data collection techniques is a crucial element of rigorous scholarship, as it can minimise threats to validity and reliability of gathered data. A failure to do so could have significant consequences for knowledge creation in the IB field (Mullen, 1995; Singh, 1995). 


\section{Dillman's framework for mail survey data collection}

Guided by social exchange theory, in the late 1970s, Don A. Dillman (1978) proposed a comprehensive framework for mail survey data collection known in the literature as the Total Design Method (ToDM). According to social exchange theory (Blau, 1964; Homans, 1973) a questionnaire recipients are most likely to complete and return a questionnaire if they expect that the perceived benefits of doing so will outweigh the perceived costs (material and psychological) of responding. Consequently, the researcher (whether in international or/and domestic market) needs to minimise the expected costs and maximise the expected benefits of participation. Three elements are crucial for reinforcing this kind of behaviour: rewards, costs, and trust. In simple terms rewards are what one anticipates to gain from a particular activity, costs are what one gives up or spends to obtain the rewards, and trust is the expectation that in the long term the rewards of doing something will offset the costs (Dillman, 1978). The most important strength of the ToDM is a set of procedures for increasing response rates and decreasing the non-response errors ${ }^{5}$.

Among those procedures, which are of a great interest for this work, four carefully spaced mailings to potential respondents are proposed. These are as followed: First, a questionnaire mailing. This questionnaire is mailed in an envelope along with a stamped and addressed return envelope and a detailed covering letter. Second, a postcard is sent out to all potential respondents once week after mailing the questionnaire, thanking them for their co-operation and reminding those who have not yet responded that it is important to co-operate. Third, two weeks later a second copy of the questionnaire is sent out to those who have not yet sent in the completed questionnaire, along with a reminder letter that their replies have not yet been received. Finally, four weeks later ${ }^{6}$ a third copy of the questionnaire is mailed, this time by certified mail to emphasize the importance of the survey. A note is also added in this procedure to remind the potential respondents of the importance of their response for the success of the survey.

Under social exchange approach, contacts that are different from previously used are generally more powerful than repetition of a previously used method. Individuals with whom the first contact was successful will not be subject to receiving a replacement questionnaire. As a result, the later contacts need to be varied in an effort to increase their effectiveness with nonrespondents. Therefore it is important, that each communication method differs from a previous one in order to convey a sense of appropriate renewal of an effort to communicate. Each of these delivery contacts, described above, builds upon past research (Dillman el al., 1974; Heberlein and Baumgartner, 1978) showing that a distinctively different final contact improves response to mail surveys. In addition, it has been shown in the literature that multiple contacts have a significantly greater 
collective capability for influencing response rates than any other technique for increasing response to mail surveys (Scott, 1961; Linsky, 1975; Dillman et al., 1978).

Taking into account the globalisation of markets, the surge of mail surveys techniques (Dillman, 1972; Dillman and Sangster, 1990), and the influence of sometimes conflicting pressures from groups with much influence over how surveys get done, Dillman (1999, 2000) modified the original ToDM in the late 1990s and called it the Tailored Design Method (TaDM). One of the new features $^{7}$ of the TaDM is the change in the number of contacts. Here the use of five not four contacts are described. The new contact that was added to the existing contacts in ToDM, and described above, represents a brief prenotice letter. This is sent to potential respondents a few days prior to mailing the questionnaire as a special mail. It aims to signal that a questionnaire for an important survey will arrive in a few days and that the person's response would be greatly appreciated.

Dillman's intention in designing each aspect of the implementation system from prenotice letter to return envelopes was to create positive salience where each element of the process is noticeable but in a way that creates a positive impression and by that increases a sense of reward, diminishes perceived costs and at the same time creates trust. The overall impression that is established depends not only on individual contacts but also on the consistency amongst those contacts. Therefore, it is important that each contact should not be thought of as self-standing but as part of an overall implementation system for which a change in one part is likely to be unintended consequences for another. In addition none of these contacts talked above should be omitted because either the ToDM or the TaDM should be seen as a package of procedures which interact with each other to produce a maximum response rate.

\section{The efficiency of Dillman's framework to cross-cultural research}

Since the development of the ToDM technique its adaptation has lead to an increase in the number of mail surveys, which have become one of the most common forms for gathering data in the business research (Dillman, 1991). Because the ToDM was developed in the United States, Goyder (1982: 533), by refereeing to Ladd's (1980) work, points out that return rates on mail surveys would be lower in foreign cultures than in the United States due to "higher legitimacy of surveying in American cultures ". However, this is no longer sufficient since there have been investigations carried out in Europe, Australia and Asia on whether the ToDM was a culture-bound survey methodology and proved otherwise. For example, Greatz (1985) assessed the feasibility of using the implementation procedures proposed by the ToDM in Australia. He found that multiple contacts with potential respondents yield to high response rates and good quality of data. His results were comparable with those obtained in the United States. De Leeuw and Hox (1988), however, analysed the efficiency of the personalisation of a covering letter and reminder by certified mail (i.e. 
response-increasing factors of the ToDM) on a sample of the Dutch population. They found that response-stimulating factors have a statistically significant effect on the number of completed questionnaires and data quality, and that response rates do not differ to any great extent from those in the USA either. Another study comparing the appropriateness of the ToDM (i.e. the usefulness of non-monetary incentives) in the Netherlands is that of Nederhof (1983). He shows that the use of an incentive positively influences the speed and quality of survey results. His results were also comparable with those in the American literature (Brennan, 1958; Watson, 1965), and at the same time indicating the cross-cultural effectiveness of the ToDM method initially developed in the United States. Rada (2000), on the other hand, examined the usefulness of Dillman's implementation procedures from the TaDM on the response rate in Spain. He found that multiple contacts do indeed increase the number of returned questionnaires. He also pointed out that his results do not greatly differ from those obtained by other researchers on efficiency of the ToDM in countries such as the United States, Netherlands and Australia. In the study of a comparison of the viability the ToDM in Japan and the United States, Jussaume and Yamada (1990) showed that "mail surveys are feasible research tool in Japan and potentially in other cultures where the majority of the intended universe is literate, can be sampled, and can be contacted through a dependable postal system (p.226)". Their results also showed that the theoretical foundations of the ToDM is not culture bound to Western countries and that consideration to the theoretical base is the key to implementing the ToDM to foreign settings.

Based on the above, the fact that methodological data obtained from different countries under similar conditions is comparable to those in the United States, suggests that the generalizability of findings may not necessarily be limited to one nation or continent as claimed by Goyder (1982).

\section{The analytical approach}

To investigate "if" and "how" IB researchers report the mail survey administration procedures, a comprehensive and systematic content analysis of Journal of International Business Studies (JIBS), International Business Review (IBR), Journal of World Business (JWB) and Management International Review (MIR) between 2000 and 2008 was carried out (Krippendorff, 2004; Weber, 1990). We choose those four journals for our review because they symbolise very highly ranked and "the key" IB specific journals and are an important part of an IB research (DuBois and Reeb, 2000). Even though, as pointed out by Platt (1996) and cited in Piekkari et al., (2009: 563), it cannot be presumed that highly ranked journals "contain a representative cross-section of publications" as they might use different categories, periods and each has its limitations. However in combinations, "they do tell something about disciplinary standards and ideas". 


\subsection{Data Collection}

The data collection process consisted of the following stages. First, all studies were identified one-by-one through individual on-line access to the journal using library's electronic resources available at authors' institutions. The only exception was MIR where studies were located using electronic access to the journal plus the examination of hard copies of special and focus issues kindly supplied to authors from the journal's editor-in-chief's office ${ }^{8}$. Second, every article (omitting editorials, commentaries and award winning) published in these four journals, in the period under investigation, was then categorised based on the type of data collection used by authors (e.g. primary, secondary or both). Within the primary data category, each article was than grouped into a questionnaire (i.e. where only a questionnaire was used for data collection) and questionnaire plus other primary data technique (e.g. interviews, focus groups) category. Further the questionnaire category was re-grouped into the following sub-categories: a mail, an electronic, a fax, a personally-administered, an internal mail and a mixed method. This was undertaken in order to examine, in more detail, the ways through which a questionnaire was delivered to potential respondents.

In situations where a distribution method was not mentioned by authors, a study was placed under the "not mentioned" category (see Table 1). This identification was based on the method or methods used for data collection by authors and reported in the methodology section of the particular papers. Finally, we coded the articles in search for the multi contact strategies developed by Dillman $(1978,1999,2000)$ as discussed above. Any confusions relating to the coding process were resolved by discussions between authors. 
Table 1 Categorisation of Journal Articles with Respect to Survey Data Collection Methods, 2000 - 2009.

\begin{tabular}{|c|c|c|c|c|c|c|c|c|c|c|c|}
\hline Year & Journal $^{1}$ & Mail (\%) & Electronic (\%) & $\begin{array}{c}\text { Personally } \\
\text { Administered (\%) }\end{array}$ & $\operatorname{Fax}(\%)$ & $\begin{array}{l}\text { Internal } \\
\text { Mail }(\%)\end{array}$ & Mixed $(\%)^{2}$ & $\begin{array}{c}\text { Not } \\
\text { Mentioned (\%) }\end{array}$ & $\begin{array}{c}\text { Total } \\
{\text { Questionnaire }(\%)^{3}}^{\text {Q }} \text { Q }\end{array}$ & $\begin{array}{c}\text { Total } \\
\text { Primary Data }\end{array}$ & $\begin{array}{l}\text { Articles } \\
\text { per Year }\end{array}$ \\
\hline 2000 & JIBS & 10 & - & - & - & - & - & - & $10(52.63)$ & 19 & 41 \\
\hline 2001 & JIBS & 16 & - & - & - & - & - & - & $16(88.89)$ & 18 & 45 \\
\hline 2002 & JIBS & $13(92.86)$ & - & - & - & - & $1(7.14)$ & - & $14(70.00)$ & 20 & 43 \\
\hline 2003 & JIBS & $6(85.71)$ & - & - & - & - & - & $1(14.29)$ & $7(50.00)$ & 14 & 37 \\
\hline 2004 & JIBS & 9 & - & - & - & - & - & - & $9(69.23)$ & 13 & 23 \\
\hline 2005 & JIBS & 5 & - & - & - & - & - & - & $5(41.67)$ & 12 & 33 \\
\hline 2006 & JIBS & 10 & - & - & - & - & - & - & $10(58.82)$ & 17 & 42 \\
\hline 2007 & JIBS & $12(92.31)$ & - & - & - & - & $1(7.69)$ & - & $13(56.52)$ & 23 & 52 \\
\hline 2008 & JIBS & 11 & - & - & - & - & - & - & $11(44.00)$ & 25 & 62 \\
\hline 2009 & JIBS & $7(70.00)$ & $1(10.00)$ & $1(10.00)$ & - & - & $1(10.00)$ & - & $10(45.45)$ & 22 & 71 \\
\hline \multicolumn{2}{|l|}{ Total } & $99(34.74)$ & $1(10.00)$ & 1(3.45) & - & - & $3(16.67)$ & $1(25.00)$ & 105(57.38) & 183 & 449 \\
\hline 2000 & IBR & $6(85.71)$ & - & - & - & - & $1(14.29)$ & - & $7(33.33)$ & 21 & 37 \\
\hline 2001 & IBR & $8(80.00)$ & - & $2(20.00)$ & - & - & - & - & $10(58.82)$ & 17 & 35 \\
\hline 2002 & IBR & $5(71.43)$ & - & $1(14.29)$ & - & - & $1(14.29)$ & - & $7(50.00)$ & 14 & 36 \\
\hline 2003 & IBR & $11(91.67)$ & - & - & - & - & $1(8.33)$ & - & $12(66.67)$ & 18 & 36 \\
\hline 2004 & IBR & $9(90.00)$ & - & $1(10.00)$ & - & - & - & - & $10(58.82)$ & 17 & 36 \\
\hline 2005 & IBR & $6(66.67)$ & - & $1(11.11)$ & - & - & $2(22.22)$ & - & $9(45.00)$ & 20 & 36 \\
\hline 2006 & IBR & $9(81.82)$ & - & $1(9.09)$ & - & - & $1(9.09)$ & - & $11(57.89)$ & 19 & 38 \\
\hline 2007 & IBR & $1(20.00)$ & $2(40.00)$ & $1(20.00)$ & - & - & $1(20.00)$ & - & $5(31.25)$ & 16 & 34 \\
\hline 2008 & IBR & $4(57.14)$ & $1(14.29)$ & $1(14.29)$ & - & - & $1(14.29)$ & - & $7(38.89)$ & 18 & 46 \\
\hline 2009 & IBR & $12(63.16)$ & $2(10.53)$ & $3(15.79)$ & - & - & $2(10.53)$ & - & $19(70.37)$ & 27 & 48 \\
\hline \multicolumn{2}{|c|}{ Total } & 71(24.91) & $5(50.00)$ & 11(37.93) & - & - & $10(55.56)$ & - & 97(51.87) & 187 & 382 \\
\hline
\end{tabular}


Table 1 Categorisation of Journal Articles with Respect to Survey Data Collection Methods, 2000 - 2009 (continued)

\begin{tabular}{|c|c|c|c|c|c|c|c|c|c|c|c|}
\hline Year & Journal & Mail (\%) & $\begin{array}{l}\text { Electronic } \\
(\%)\end{array}$ & $\begin{array}{c}\text { Personally } \\
\text { Administered (\%) }\end{array}$ & $\operatorname{Fax}(\%)$ & $\begin{array}{l}\text { Internal } \\
\text { Mail(\%) }\end{array}$ & Mixed (\%) & $\begin{array}{c}\text { Not } \\
\text { Mentioned (\%) }\end{array}$ & $\begin{array}{c}\text { Total } \\
\text { Questionnaire\%) }\end{array}$ & $\begin{array}{c}\text { Total } \\
\text { Primary Data }^{4}\end{array}$ & $\begin{array}{l}\text { Articles } \\
\text { per Year }\end{array}$ \\
\hline 2000 & JWB & 5 & - & - & - & - & - & - & $5(45.45)$ & 11 & 23 \\
\hline 2001 & JWB & $3(60.00)$ & - & $2(40.00)$ & - & - & - & - & $5(35.71)$ & 14 & 22 \\
\hline 2002 & JWB & 4 & - & - & - & - & - & - & $4(40.00)$ & 10 & 25 \\
\hline 2003 & JWB & $4(80.0)$ & - & $1(20.00)$ & - & - & - & - & $5(33.33)$ & 15 & 27 \\
\hline 2004 & JWB & $6(75.00)$ & - & $2(25.00)$ & - & - & - & - & $8(50.00)$ & 16 & 30 \\
\hline 2005 & JWB & $4(80.00)$ & - & $1(20.00)$ & - & - & - & - & $5(33.33)$ & 15 & 28 \\
\hline 2006 & JWB & $7(63.64)$ & - & $3(27.27)$ & - & - & $1(9.09)$ & - & $11(64.71)$ & 17 & 28 \\
\hline 2007 & JWB & $8(88.89)$ & - & 1(11.11) & - & - & - & - & $9(60.00)$ & 15 & 34 \\
\hline 2008 & JWB & $7(77.78)$ & $1(11.11)$ & - & - & - & $1(11.11)$ & - & $9(56.25)$ & 16 & 33 \\
\hline 2009 & JWB & $12(80.00)$ & $1(6.67)$ & $1(6.67)$ & $1(6.67)$ & - & - & - & $15(75.00)$ & 20 & 39 \\
\hline \multicolumn{2}{|l|}{ Total } & $60(21.05)$ & $2(20.00)$ & 11(37.93) & 1(100.00) & - & 2(11.11) & - & $76(51.01)$ & 149 & 289 \\
\hline 2000 & MIR & $5(83.33)$ & - & $1(16.67)$ & - & - & - & - & $6(60.00)$ & 10 & 21 \\
\hline 2001 & MIR & 4 & - & - & - & - & - & - & $4(40.00)$ & 10 & 16 \\
\hline 2002 & MIR & $7(70.00)$ & - & - & - & - & $1(10.00)$ & $2(20.00)$ & $10(58.82)$ & 17 & 28 \\
\hline 2003 & MIR & $4(50.00)$ & - & $3(37.50)$ & - & - & $1(12.50)$ & - & $8(47.06)$ & 17 & 39 \\
\hline 2004 & MIR & $9(90.00)$ & - & $1(10.00)$ & - & - & - & - & $10(52.63)$ & 19 & 41 \\
\hline 2005 & MIR & $6(60.00)$ & $1(10.00)$ & $1(10.00)$ & - & $1(10.00)$ & $1(10.00)$ & - & $10(58.82)$ & 17 & 42 \\
\hline 2006 & MIR & 5 & - & - & - & - & - & - & $5(35.71)$ & 14 & 31 \\
\hline 2007 & MIR & $8(88.89)$ & 1(11.11) & - & - & - & - & - & $9(81.82)$ & 11 & 36 \\
\hline 2008 & MIR & 3 & - & - & - & - & - & - & $3(37.50)$ & 8 & 32 \\
\hline 2009 & MIR & $4(80.00)$ & - & - & - & - & - & $1(20.00)$ & $5(50.00)$ & 10 & 34 \\
\hline \multicolumn{2}{|c|}{ Total } & $55(19.30)$ & $2(20.00)$ & 6(20.69) & & $1(100.00)$ & $3(16.67)$ & $3(75.00)$ & $70(52.63)$ & 133 & 320 \\
\hline \multicolumn{2}{|c|}{ Grand Total } & 285(81.90) & $10(2.87)$ & 29(8.33) & 1(0.29) & 1(0.29) & 18(5.17) & $4(1.15)$ & 348(53.37) & 652 & 1440 \\
\hline
\end{tabular}

Note:

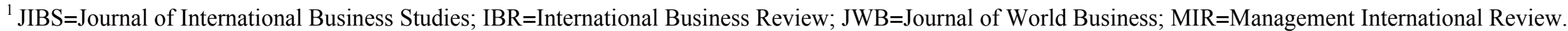

${ }^{2}$ Where two or more methods were used together (e.g. a mail and personally-administered survey, a mail, fax and personally-administered survey).

${ }^{3}$ Studies that only used a questionnaire as a primary data collection method.

${ }^{4}$ Primary data was only used (e.g. interviews, experiment, focus groups) for collecting data.

Source: Authors' calculations 
As shown in Table 1, 652 out of 1440 papers published in four journals, under the investigation period, used a primary data collection, accounting for 45 percent. In total, 348 (53\%) of 652 studies were identified as those that used a questionnaire as their only data collection method. It can also be seen from Table 1 that the three most common ways of sending a questionnaire to potential responders, amongst authors in the four journals together, were by post $(82 \%)$, followed by personally-administered delivery $(8 \%)$ and a mixed-method approach $(5 \%)$. Further, three (1\%) studies out of 348 failed to mention how a questionnaire was delivered.

In order to examine our objectives, we decided to include only studies that utilised a mail survey as a primary data collection method for the following reasons. First, the fact that mail surveys are still a popular way of gathering data amongst IB researchers (Yang et al., 2006). Second, the theoretical framework proposed by Dillman in 1978 was developed for postal survey data collection. Finally, a large number of studies used this type of data collection technique in our sample.

Based on the above criterias, 285 articles were included in our analysis. As indicated in Table 1 , JIBS offered the largest number of articles ( 99 or $35 \%$ ), followed by IBR ( 71 or $25 \%$ ), then JWB $(60,21 \%)$, and MIR (55 or 19\%). A list of the sample articles is available from the corresponding author.

We selected a time period of 2000 - 2009 to examine how well international business researchers have reported data collection procedures for mail surveys in the last decade. The year 2000 was chosen to be a departure point, as the publication year of Dillman's book (Dillman, 2000) where he modified his original framework into the TaDM.

Sample's characteristics presented in Table 2 point out that in $228(80 \%)$ of the papers the corresponding author was a male and in only $57(20 \%)$ of the papers, a female. In majority of the studies (132 or 46\%) the corresponding author was a professor, followed by an assistant professor (77 or $27 \%$ ), and an associate professor $(69,24 \%)$. In most of the papers $(110$ or $39 \%)$ the corresponding author was located in Europe, followed by North-America (97 or 34\%), and Asia (54 or $19 \%$ ). The largest percentage of the European authors (43 or 39\%) was from the UK, followed by Denmark and Spain (10 or 9\% each) ${ }^{9}$. The majority of articles were written by two authors (119 or $42 \%$ ), followed by three authors (73 or $26 \%$ ), and a single authorship (55 or $19 \%$ ). The most frequent number of countries surveyed by authors was one (160 or 56\%), followed by more than three ( 66 or $23 \%$ ), and two (32 or 11\%). The continent most surveyed by authors was Europe ( 82 or $29 \%$ ), followed by Asia (24\%), and America (39 or 14\%). More than half of the studies under investigation (183 or 64\%) did not mention the used a pilot study to pre-test the postal questionnaire. The most reported response rate by authors was between 20 to 29.99 percent (57 
papers, 20\%), and the mean response rate was 38\%. A higher percentage than that obtained by Yang et al., (2006) for postal surveys across IB journals between $1992-2003$.

Table 2. Sample Characteristics.

\begin{tabular}{|c|c|c|c|}
\hline & Cateoories & Total $(n=285)$ & Mean (Std dev) \\
\hline \multicolumn{4}{|l|}{$\begin{array}{l}\text { Corresponding Author's } \\
\text { Characteristics }\end{array}$} \\
\hline Gender & $\begin{array}{l}\text { Male } \\
\text { Female }\end{array}$ & $\begin{array}{c}228(80.00) \\
57(20.00)\end{array}$ & $0.20(0.40)$ \\
\hline Position & $\begin{array}{l}\text { Assistant Professor } \\
\text { Associate Professor } \\
\text { Professor } \\
\text { PhD Student } \\
\text { Non-academic }\end{array}$ & $\begin{array}{c}77(27.02) \\
69(24.21) \\
132(46.23) \\
4(1.40) \\
3(1.05)\end{array}$ & $2.26(0.94)$ \\
\hline Country & $\begin{array}{l}\text { North-America } \\
\text { South-America } \\
\text { Europe }^{2} \\
\text { Asia }^{3} \\
\text { Oceania }^{4}\end{array}$ & $\begin{array}{c}97(34.04) \\
3(1.05) \\
110(38.60) \\
54(18.95) \\
21(7.37)\end{array}$ & $2.91(1.67)$ \\
\hline Number of Countries Surveyed & $\begin{array}{l}\text { One Country } \\
\text { Two Countries } \\
\text { Three Countries } \\
\text { More than Three Countries } \\
\text { Not Clear How Many }\end{array}$ & $\begin{array}{c}160(56.14) \\
32(11.23) \\
19(6.67) \\
66(23.16) \\
8(2.81)\end{array}$ & $2.05(1.35)$ \\
\hline Number of Continents Surveyed & 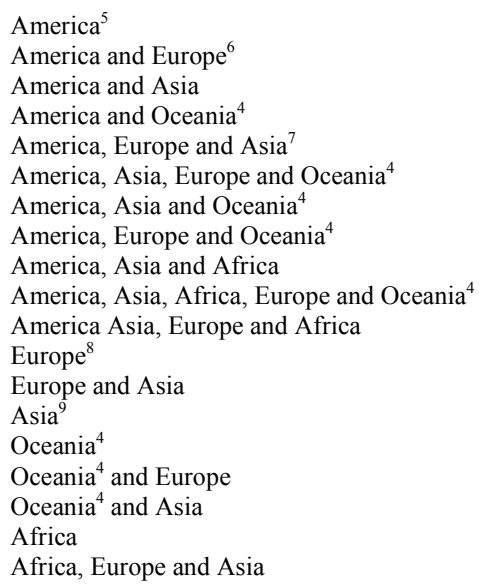 & $\begin{array}{l}39(13.68) \\
15(5.26 \\
9(3.16) \\
1(0.35) \\
30(10.53) \\
6(2.11) \\
2(0.70) \\
2(0.70) \\
3(1.05) \\
1(0.35) \\
2(0.70) \\
82(28.77) \\
5(1.75) \\
67(23.51) \\
7(2.46) \\
3(1.05) \\
8(2.81) \\
2(0.70) \\
1(0.35)\end{array}$ & $10.75(6.16)$ \\
\hline Pilot Study & $\begin{array}{l}\text { Not referred } \\
\text { Referred }\end{array}$ & $\begin{array}{l}183(64.21) \\
102(35.79)\end{array}$ & $0.36(0.48)$ \\
\hline Response Rate & $\begin{array}{l}\text { Less than } 10 \% \\
10 \text { to } 19.99 \% \\
20 \text { to } 29.99 \% \\
30 \text { to } 39.99 \% \\
40 \text { to } 49.99 \% \\
50 \text { to } 59.99 \% \\
60 \text { to } 69.99 \% \\
70 \text { to } 79.99 \% \\
80 \text { to } 89.99 \% \\
90 \text { to } 99.99 \% \\
\text { Not Mentioned }\end{array}$ & $\begin{array}{c}20(7.02) \\
27(9.47) \\
57(20.00) \\
43(15.09) \\
33(11.58) \\
14(4.91) \\
9(3.16) \\
7(2.46) \\
5(1.75) \\
2(0.70) \\
68(23.86) \\
\end{array}$ & $37.52(20.72)^{10}$ \\
\hline
\end{tabular}

Notes:

${ }^{1}$ Ninety two percent of the North-American authors were based in the USA.

${ }^{2}$ Thirty nine percent of the European authors were from the UK. This was followed by nine percent of authors from Denmark and Spain.

${ }^{3}$ Fifty four percent of the Asian authors were located in China. 
${ }^{4}$ Mainly Australia and New Zealand.

${ }^{5}$ America was the third most often surveyed continent amongst studies that surveyed one country.

${ }^{6}$ America and Europe were the third most often surveyed continents amongst studies that surveyed more than one country.

${ }^{7}$ America, Europe and Asia were the most often surveyed continents amongst studies that surveyed more than one country.

${ }^{8}$ Europe was the second most often surveyed continent for that surveyed one and more than one country.

${ }^{9}$ Asia was the most often surveyed continent for studies that surveyed one country.

${ }^{10}$ Based on the number reported by authors and expressed in the form of a percentage. In the case of a cross-country study, the mean response rate was included.

${ }^{11}$ Here we mean studies where authors did not express the response rate in the form of a percentage.

Source: Authors' calculations

\section{Results}

\subsection{Across Journals}

As demonstrated in Table 3, only 14 of the 285 articles under investigation referred to Dillman's ToDM and/or TaDM for the mail survey administration procedures. However, there are no statistically significant differences between studies that mentioned or not mentioned Dillman's frameworks. The journals with the most authors referring to those frameworks were MIR (5 studies), followed by JIBS and IBR (4 and 3 studies, respectively). Out of the 14 studies that mentioned Dillman's work, only 6 studies (43\%) did actually mention the survey data collection procedures. 
Table 3 Reporting of Data Collection Procedures Across Journals, 2000-2009 ${ }^{1}$.

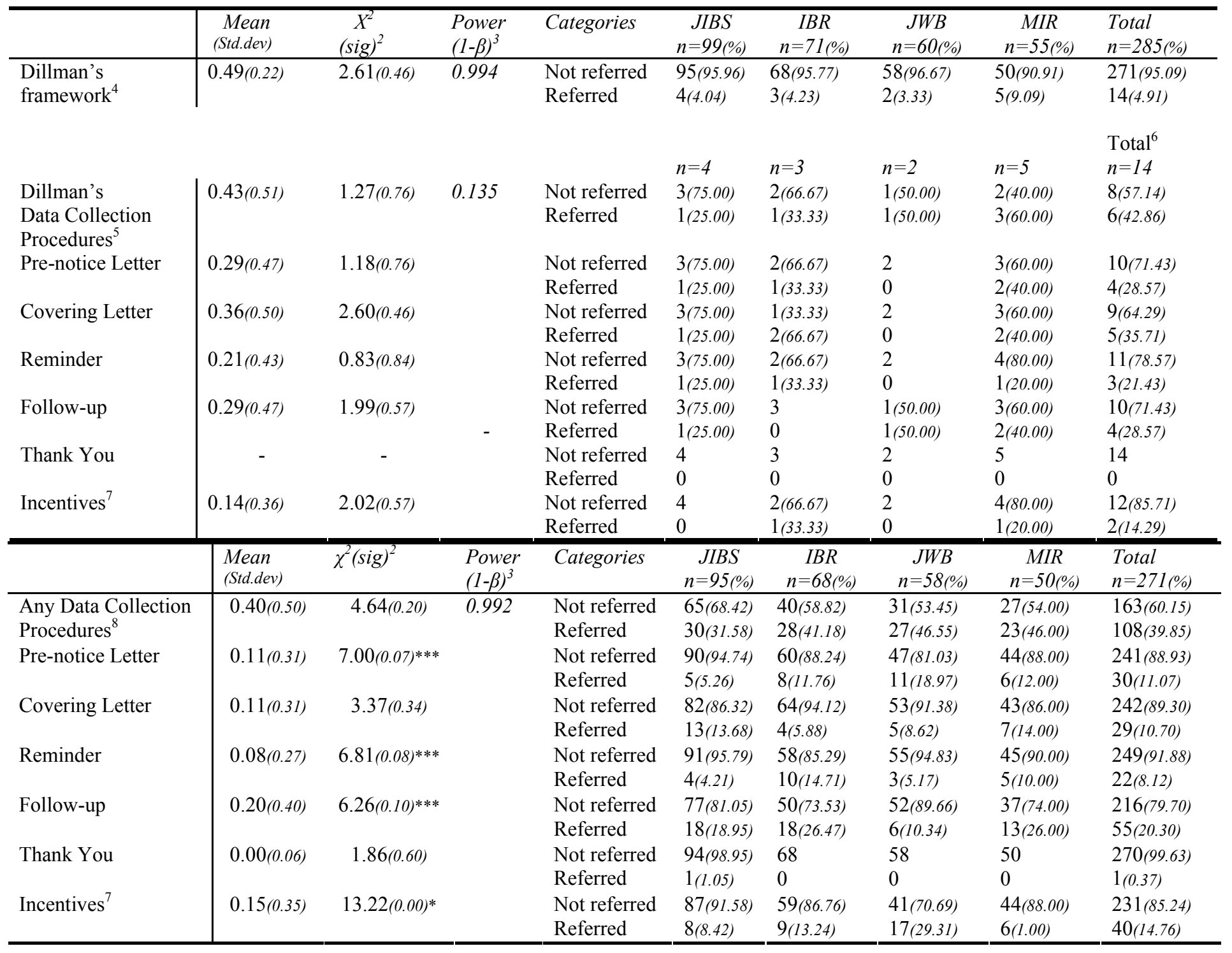


Notes:

${ }^{1}$ Table adopted from Hult et al., (2008). To enhance readability and comparability of data for statistical testing, percentages for 0 s are not reported.

${ }^{2}$ The Fisher tests were undertaken to confirm these results.

${ }^{3}$ Following the work of Brock (2003), a post hoc statistical power analysis was calculated using G*Power developed

by Faul et al., $(2009,2007)$ and available from http://www.psycho.uniduesseldorf.de/abteilungen/aap/gpower3/. $\quad \alpha=0.05$

${ }^{4}$ Dillman's ToDM and/or TaDM mentioned or not for data collection procedures.

${ }^{5}$ Mail survey data collection procedures proposed in Dillman's frameworks.

${ }^{6} \mathrm{We}$ acknowledge the fact that 14 studies is a small sample size for a statistical analysis, but this is for illustration purposes to show

how many studies that refer to Dillman's frameworks actually reported the survey data collection procedures that he proposed in ToDM and/or TaDM

${ }^{7}$ Both monetary and non-monetary.

${ }^{8}$ Mail survey data collection procedures referred or not, when Dillman's framework not mentioned for data collection procedures.

$* \mathrm{p} \leq 0.01 ; * * \mathrm{p} \leq 0.05 ; * * * \mathrm{p} \leq 0.10$

Source: Authors' own calculations.

An examination across journals between those 14 studies that mentioned Dillman's framework, (see Table 3), showed that MIR was the journal with the most studies (3 or 60\%) referring to data collection procedures, while the other three journals included only one study each ( 1 or $17 \%$ ). The contact strategies mostly used by authors in MIR were a pre-notice letter, a covering letter and a follow-up ( 2 studies or $40 \%$ each). Overall across journals, however, the most frequent data collection procedure mentioned, amongst the 14 studies that referred to Dillman's work, was a covering letter ( 5 or $36 \%$ ), and the least frequent procedures mentioned were incentives ( 2 or 14\%). An interesting finding here is that none of the studies across journals mentioned the use of a thank you letter as a data collection procedure despite the fact that Dillman $(1978,1999)$ states that this is an important element of a survey implementation strategy.

Based on our above findings, for further analysis across journals, we decided to exclude those 14 articles that mentioned Dillman's framework to examine "if" and "how" researchers in international business report the mail survey administration procedures without mentioning Dillman's work. The results form the remaining portion of Table 3 and we titled them as any data collection procedures from now on. It can be seen from this table that 108 (40\%) out of 271 mail survey studies reported data collection procedures of any kind, and that the highest number of studies reported was in JIBS (30 or 32\%), followed by IBR (28 or 41\%) and JWB (27 or 47\%). The findings indicate that there are no statistically significant differences in the reporting or not reporting of any multi contact strategies across journals. In general, the most frequent data collection procedures used for studies that did not referred to Dillman's framework for mail survey administration were follow-ups (55 or $20 \%$ ), followed by incentives (40 or 15\%) and a covering 
letter (11\%). Looking at the findings in Table 3 it can be seen that statistically significant results, across journals, where found for reporting incentives $\left(\chi^{2}=13.22, p=0.00\right)$, a pre-notice letter $\left(\chi^{2}=7.00, p=0.07\right)$, a reminder $\left(\chi^{2}=6.81, p=0.08\right)$ and follow-ups $\left(\chi^{2}=6.26, p=0.10\right)$. JWB included the most studies that reported a pre-notice letter (11 or 19\%) and incentives (17 or 29\%). IBR contained the biggest amount of articles that used reminders (10 or 15\%). However, both IBR and JIBS included the highest number of studies that mentioned follow-ups (18 or 19\% and 18 or $27 \%$, respectively). As indicated in this part of Table 3, there was only one study (1\%), published in JIBS, which reported a thank you letter as a mail survey administration procedure.

\subsection{Across Years}

As shown in Table 4, statistically significant differences were found between studies that did and did not report Dillman's framework for the postal surveys data collection process across years $\left(\chi^{2}=17.22, p=0.04\right)$. Out of the 14 studies that mentioned Dillman's framework for the mail survey administration procedures, the highest annual percentage of reporting such approach amongst studies was in 2004 ( $15 \%$ or 5) followed by 2007 (14\% or 4 ). Of the five studies published in 2004, three $(60 \%)$ actually mentioned the mail survey data collection procedures, and of the four studies published in 2007 only one (25\%) referred to such strategies. The most popular contact procedure used by authors that referred to Dillman's work in 2004 was a follow-up ( 2 studies or $40 \%$ ).

Table 4 also reveals that between 2000 and 2009, only $108(40 \%)$ out of 271 studies mentioned any data collection procedures for mail survey of any kind. It can also be seen that within those 108 studies, the years from 2006 to 2009 included the most studies (13) that mentioned any data collection procedures, and the year 2001 included the least studies (7). Further, our finding across years point out that statistically significant result was found (i.e. amongst studies that mentioned any data collection procedures) only for reporting a covering letter as a data collection strategy for mail surveys $\left(\chi^{2}=15.03, \mathrm{p}=0.09\right)$. 
Table 4 Reporting of Data Collection Procedure Across Years, 2000-2009 ${ }^{1}$.

\begin{tabular}{|c|c|c|c|c|c|c|c|c|c|c|c|c|c|c|c|}
\hline & $\begin{array}{c}\text { Mean } \\
\text { (Std.dev) } \\
\end{array}$ & $\begin{array}{c}\chi^{2} \\
(\text { sig })^{2}\end{array}$ & $\begin{array}{l}\text { Power } \\
(1-\beta)^{3}\end{array}$ & Categories & $\begin{array}{c}2000 \\
n=26(\%)\end{array}$ & $\begin{array}{c}2001 \\
n=31(\%) \\
\end{array}$ & $\begin{array}{c}2002 \\
n=29(\%)\end{array}$ & $\begin{array}{c}2003 \\
n=25(\%)\end{array}$ & $\begin{array}{c}2004 \\
n=33(\%)\end{array}$ & $\begin{array}{c}2005 \\
n=21(\%) \\
\end{array}$ & $\begin{array}{c}2006 \\
n=31(\%)\end{array}$ & $\begin{array}{l}2007 \\
n=29(\%) \\
\end{array}$ & $\begin{array}{l}2008 \\
n=25(\%) \\
\end{array}$ & $\begin{array}{l}2009 \\
n=35(\%) \\
\end{array}$ & $\begin{array}{l}\text { Total } \\
n=285(\%)\end{array}$ \\
\hline \multirow{2}{*}{$\begin{array}{l}\text { Dillman's } \\
\text { framework }^{4}\end{array}$} & $\begin{array}{c}0.49 \\
(0.22)\end{array}$ & $\begin{array}{c}17.22 \\
(0.04)^{* *}\end{array}$ & 0.967 & Not referred & 26 & $30(96.77)$ & $28(96.55)$ & $24(96.00)$ & $28(84.85)$ & $20(95.24)$ & 31 & $25(86.21)$ & 25 & $34(95.09)$ & 271 (95.09) \\
\hline & & & & & $n=0$ & $n=1(\%)$ & $n=1(\%)$ & $n=1(\%)$ & $n=5(\%)$ & $n=1(\%)$ & $n=0$ & $n=4(\%)$ & $n=0$ & $n=1(\%)$ & $\begin{array}{l}\text { Total }^{6} \\
n=14(\%)\end{array}$ \\
\hline Dillman's & 0.43 & 6.04 & 0.107 & Not referred & 0 & 1 & 1 & 0 & $2(40.00)$ & 1 & 0 & $3(75.00)$ & 0 & 0 & $8(57.14)$ \\
\hline $\begin{array}{l}\text { Data } \\
\text { Collection } \\
\text { Procedures }^{5}\end{array}$ & $(0.51)$ & $(0.42)$ & & Referred & 0 & 0 & 0 & 1 & $3(60.00)$ & 0 & 0 & $1(25.00)$ & 0 & 1 & $6(42.86)$ \\
\hline Pre-notice & 0.29 & 10.1 & & Not referred & 0 & 1 & 0 & 0 & $4(80.00)$ & 1 & 0 & 4 & 0 & 0 & $10(71.43)$ \\
\hline Letter & $(0.47)$ & $(0.12)$ & & Referred & 0 & 0 & 1 & 1 & $1(20.00)$ & 0 & 0 & 0 & 0 & 1 & $4(28.57)$ \\
\hline Covering & 0.36 & 7.25 & & Not referred & 0 & 1 & 0 & 0 & $4(80.00)$ & 1 & 0 & $3(75.00)$ & 0 & 0 & $9(64.29)$ \\
\hline Letter & $(0.50)$ & $(0.30)$ & & Referred & 0 & 0 & 1 & 1 & $1(20.00)$ & 0 & 0 & $1(25.00)$ & 0 & 1 & $5(35.71)$ \\
\hline \multirow[t]{2}{*}{ Reminder } & 0.21 & 4.80 & & Not referred & 0 & 1 & 1 & 0 & $4(80.00)$ & 1 & 0 & $3(75.00)$ & 0 & 1 & $11(78.57)$ \\
\hline & $(0.43)$ & $(0.57)$ & & Referred & 0 & 0 & 0 & 1 & $1(20.00)$ & 0 & 0 & $1(25.00)$ & 0 & 0 & $3(21.43)$ \\
\hline \multirow[t]{2}{*}{ Follow-up } & 0.29 & 8.12 & & Not referred & 0 & 1 & 1 & 0 & $3(60.00)$ & 1 & 0 & 4 & 0 & 0 & $10(71.43)$ \\
\hline & $(0.47)$ & $(0.23)$ & - & Referred & 0 & 0 & 0 & 1 & $2(40.00)$ & 0 & 0 & 0 & 0 & 1 & $4(28.57)$ \\
\hline \multirow[t]{2}{*}{ Thank you } & . & - & & Not referred & 0 & 1 & 1 & 1 & 5 & 1 & 0 & 4 & 0 & 1 & 14 \\
\hline & & & & Referred & 0 & 0 & 0 & 0 & 0 & 0 & 0 & 0 & 0 & 0 & 0 \\
\hline \multirow[t]{3}{*}{ Incentives $^{7}$} & 0.14 & 1.34 & & Not referred & 0 & 1 & 1 & 1 & $4(80.00)$ & 1 & 0 & $3(75.00)$ & 0 & 1 & $12(85.71)$ \\
\hline & $(0.14)$ & $(0.97)$ & & Referred & 0 & 0 & 0 & 0 & $1(20.00)$ & 0 & 0 & $1(25.00)$ & 0 & 0 & $2(14.29)$ \\
\hline & $\begin{array}{c}\text { Mean } \\
\text { (Std.dev) }\end{array}$ & $\begin{array}{c}\chi^{2} \\
(\text { sig })^{2}\end{array}$ & $\begin{array}{l}\text { Power } \\
(1-\beta)^{3}\end{array}$ & Categories & $\begin{array}{c}2000 \\
n=26(\%)\end{array}$ & $\begin{array}{c}2001 \\
n=30(\%)\end{array}$ & $\begin{array}{c}2002 \\
n=28(\%)\end{array}$ & $\begin{array}{c}2003 \\
n=24(\%)\end{array}$ & $\begin{array}{c}2004 \\
n=28(\%)\end{array}$ & $\begin{array}{c}2005 \\
n=20(\%)\end{array}$ & $\begin{array}{c}2006 \\
n=31(\%)\end{array}$ & $\begin{array}{l}2007 \\
n=25(\%)\end{array}$ & $\begin{array}{l}2008 \\
n=25(\%)\end{array}$ & $\begin{array}{l}2009 \\
n=34(\%)\end{array}$ & $\begin{array}{l}\text { Total } \\
n=271(\%)\end{array}$ \\
\hline Any Data & 0.40 & 9.51 & 0.957 & Not referred & $17(65.38)$ & $23(76.67)$ & $16(57.14)$ & $12(50.00)$ & $20(71.43)$ & $12(60.00)$ & $18(58.06)$ & $12(48.00)$ & $12(48.00)$ & $21(61.76)$ & $163(60.15)$ \\
\hline $\begin{array}{l}\text { Collection } \\
\text { Procedures }^{8}\end{array}$ & $(0.50)$ & (0.39) & & Referred & $9(34.62)$ & $7(23.33)$ & $12(42.86)$ & $12(50.00)$ & $8(28.57)$ & $8(40.00)$ & $13(41.94)$ & $13(52.00)$ & $13(52.00)$ & $13(38.24)$ & $108(39.85)$ \\
\hline Pre-notice & 0.11 & 5.45 & & Not referred & $23(88.46)$ & $27(90.00)$ & $25(89.29)$ & $22(91.67)$ & $25(89.29)$ & 20 & $27(87.10)$ & $23(92.00)$ & $20(80.00)$ & $29(85.29)$ & 241(88.93) \\
\hline Letter & $(0.31)$ & $(0.80)$ & & Referred & $3(11.54)$ & $3(10.00)$ & $3(10.71)$ & $2(8.33)$ & $3(10.71)$ & 0 & $4(12.40)$ & $2(8.00)$ & $5(20.00)$ & $5(14.71)$ & $30(11.07)$ \\
\hline Covering & 0.11 & 15.03 & & Not referred & $19(73.08)$ & $29(96.67)$ & $25(89.29)$ & $20(83.33)$ & $25(89.29)$ & $17(85.00)$ & $30(96.77)$ & $21(84.00)$ & $23(92.00)$ & $33(97.06)$ & $242(89.30)$ \\
\hline Letter & $(0.31)$ & $(0.09) * *$ & & Referred & $7(26.92)$ & $1(3.33)$ & $3(10.71)$ & $4(16.67)$ & $3(10.71)$ & $3(15.00)$ & $1(3.23)$ & $4(16.00)$ & $2(8.00)$ & $1(2.94)$ & $29(10.70)$ \\
\hline \multirow[t]{2}{*}{ Reminder } & 0.08 & 5.55 & & Not referred & $24(92.31)$ & $27(90.00)$ & $27(96.43)$ & $20(83.33)$ & $27(96.43)$ & $18(90.00)$ & $28(90.32)$ & $22(88.00)$ & $24(96.00)$ & $32(94.12)$ & $249(91.88)$ \\
\hline & $(0.27)$ & $(0.78)$ & & Referred & $2(7.69)$ & $3(10.00)$ & $1(3.57)$ & $4(16.67)$ & $1(3.57)$ & $2(10.00)$ & $3(9.68)$ & $3(12.00)$ & $1(4.00)$ & $2(5.88)$ & $22(8.12)$ \\
\hline \multirow[t]{2}{*}{ Follow-up } & 0.20 & 8.18 & & Not referred & $21(80.77)$ & $24(80.00)$ & $24(85.71)$ & $16(66.67)$ & $24(85.71)$ & 19 & $23(74.19)$ & $18(72.00)$ & $20(80.00)$ & $27(79.41)$ & $216(79.70)$ \\
\hline & $(0.40)$ & $(0.51)$ & & Referred & $5(19.23)$ & $6(20.00)$ & $4(14.29)$ & $8(33.33)$ & $4(14.29)$ & 0 & $8(25.81)$ & $7(28.00)$ & $5(20.00)$ & $7(20.59)$ & $55(20.30)$ \\
\hline \multirow[t]{2}{*}{ Thank you } & 0.00 & 8.86 & & Not referred & 26 & 30 & $27(96.43)$ & 24 & 28 & 20 & 31 & 25 & 25 & 34 & $270(99.63)$ \\
\hline & $(0.06)$ & $(0.46)$ & & Referred & 0 & 0 & $1(3.57)$ & 0 & 0 & 0 & 0 & 0 & 0 & 0 & $1(0.37)$ \\
\hline \multirow[t]{2}{*}{ Incentives $^{7}$} & 0.15 & 8.54 & & Not referred & $22(84.62)$ & $28(93.33)$ & $21(75.00)$ & $20(83.33)$ & $26(92.86)$ & $17(85.00)$ & $27(87.10)$ & $20(80.00)$ & $19(76.00)$ & $31(91.18)$ & $231(85.24)$ \\
\hline & $(0.35)$ & $(0.48)$ & & Referred & $4(15.38)$ & $2(6.67)$ & $7(25.00)$ & $4(16.67)$ & $2(7.14)$ & $3(15.00)$ & $4(12.90)$ & $5(20.00)$ & $6(24.00)$ & $3(8.82)$ & $40(14.76)$ \\
\hline
\end{tabular}

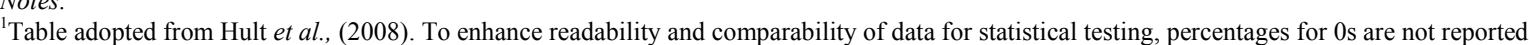

'The Fisher's exact tests were undertaken to confirm obtained results.

Following the work of Brock (2003), a post hoc statistical power analysis was calculated using G*Power developed by Faul et al., $(2009,2007)$

and available from http://www.psycho.uni-duesseldorf.de/abteilungen/aap/gpower3/. $\alpha=0.05$

'Dillman's ToDM and/or TaDM mentioned or not for data collection procedures.

${ }^{5}$ Mail survey data collection procedures proposed in Dillman's frameworks.

We acknowledge the fact that 14 studies is a small sample size for a statistical analysis, but this is for illustration purposes to show

how many studies that refer to Dillman's frameworks actually report the survey data collection procedures that he proposed in ToDM and/or TaDM 
Both monetary and non-monetary.

${ }^{8}$ Mail survey data procedures referred or not when Dillman's framework not mentioned for data collection procedures.

$* \mathrm{p} \leq 0.01 ; * * \mathrm{p} \leq 0.05 ; * * * \mathrm{p} \leq 0.10$

Source: Authors' own calculations.

\subsection{By the Number of Countries Surveyed}

Table 5 displays, the results of either reporting or not reporting mail survey data collection procedures across four journals by the number of countries surveyed by authors ${ }^{10}$.

Table 5. Reporting of Data Collection Procedures Across Journals by the Number of Countries Surveyed, 2000-2009

\begin{tabular}{|c|c|c|c|c|c|c|c|c|c|}
\hline & $\begin{array}{l}\text { Mean } \\
\text { (Std.dev) }\end{array}$ & $\chi^{2}(\text { sig })^{3}$ & $\begin{array}{l}\text { Power } \\
(1-\beta)^{4}\end{array}$ & Categories & $J I B S$ & $\overline{I B R}$ & $J W B$ & $M I R$ & Total \\
\hline One Country Surveyed & & & & & $n=45(\%)$ & $n=43(\%)$ & $n=35(\%)$ & $n=37(\%)$ & $n=160(\%)$ \\
\hline \multirow{2}{*}{ Data Collection Procedures } & $0.48(0.50)$ & $5.14(0.16)$ & 0.905 & Not referred & $29(64.44)$ & $23(53.49)$ & $15(42.86)$ & $16(43.24)$ & $83(51.88)$ \\
\hline & & & & Referred & $16(35.56)$ & $20(46.51)$ & $20(57.14)$ & $21(56.76)$ & $77(48.13)$ \\
\hline \multirow[t]{2}{*}{ Pre-notice Letter } & $0.16(0.37)$ & $5.46(0.14)$ & & Not referred & $40(88.89)$ & $38(88.37)$ & $25(71.43)$ & $31(83.78)$ & $134(83.75)$ \\
\hline & & & & Referred & $5(11.11)$ & $5(11.63)$ & $10(28.57)$ & $6(16.22)$ & $26(16.25)$ \\
\hline \multirow[t]{2}{*}{ Covering Letter } & $0.13(0.33)$ & $3.47(0.33)$ & & Not referred & $38(84.44)$ & $40(93.02)$ & $32(91.43)$ & $30(81.08)$ & $140(87.50)$ \\
\hline & & & & Referred & $7(15.59)$ & $3(6.98)$ & $3(8.57)$ & $7(18.92)$ & $20(12.50)$ \\
\hline \multirow[t]{2}{*}{ Reminder } & $0.13(0.33)$ & $7.75(0.05) * *$ & & Not referred & $41(97.62)$ & $32(76.19)$ & $30(90.91)$ & $28(87.50)$ & $131(87.92)$ \\
\hline & & & & Referred & $1(2.38)$ & $10(23.81)$ & $3(9.09)$ & $4(12.50)$ & $18(12.08)$ \\
\hline \multirow[t]{2}{*}{ Follow-up } & $0.26(0.44)$ & $3.47(0.33)$ & & Not referred & $35(77.78)$ & $31(72.09)$ & $29(82.86)$ & $24(64.86)$ & $119(74.38)$ \\
\hline & & & & Referred & $10(22.22)$ & $12(27.91)$ & $6(17.14)$ & $13(35.14)$ & $41(25.62)$ \\
\hline Thank You & - & - & & $\begin{array}{l}\text { Not referred } \\
\text { Referred }\end{array}$ & - & . & 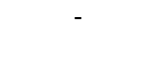 & - & \\
\hline \multirow[t]{2}{*}{ Incentives $^{5}$} & $0.16(0.37)$ & $8.09(0.04)^{* *}$ & & Not referred & $41(91.11)$ & $37(86.05)$ & $24(68.57)$ & $32(86.49)$ & $134(83.75)$ \\
\hline & & & & Referred & $4(8.89)$ & $6(13.95)$ & $11(31.43)$ & $5(13.51)$ & $26(16.25)$ \\
\hline \multicolumn{2}{|c|}{ More than One Country Surveyed } & & & & $n=54(\%)$ & $n=25(\%)$ & $n=25 \%)$ & $n=13(\%)$ & $n=117(\%)$ \\
\hline \multirow[t]{2}{*}{ Data Collection Procedures } & $0.30(0.46)$ & $0.26(0.97)$ & 0.785 & Not referred & $39(72.22)$ & $17(68.00)$ & $17(68.00)$ & $9(69.23)$ & $82(70.09)$ \\
\hline & & & & Referred & $15(27.78)$ & $8(32.00)$ & $8(32.00)$ & $4(30.77)$ & $35(29.91)$ \\
\hline \multirow[t]{2}{*}{ Pre-notice Letter } & $0.60(0.24)$ & $6.34(0.10)^{* * *}$ & & Not referred & $53(98.15)$ & $21(84.00)$ & $24(96.00)$ & $12(92.31)$ & $110(94.02)$ \\
\hline & & & & Referred & $1(1.85)$ & $4(16.00)$ & $4(4.00)$ & $1(7.69)$ & $7(5.98)$ \\
\hline \multirow[t]{2}{*}{ Covering Letter } & $0.11(0.32)$ & $0.57(0.90)$ & & Not referred & $47(87.04)$ & $22(88.00)$ & $23(92.00)$ & $11(84.62)$ & 103(88.03) \\
\hline & & & & Referred & $7(12.96)$ & $3(12.00)$ & $2(8.00)$ & 2(15.38) & $14(11.97)$ \\
\hline \multirow[t]{2}{*}{ Reminder } & $0.04(0.20)$ & $1.71(0.64)$ & & Not referred & $51(94.44)$ & $24(96.00)$ & 25 & $12(92.31)$ & $112(95.73)$ \\
\hline & & & & Referred & $3(5.56)$ & $1(4.00)$ & 0 & $1(7.69)$ & $5(4.27)$ \\
\hline \multirow[t]{2}{*}{ Follow-up } & $0.14(0.35)$ & $2.92(0.40)$ & & Not referred & $46(85.19)$ & $20(80.00)$ & $24(96.00)$ & $11(84.62)$ & 101(86.32) \\
\hline & & & & Referred & $8(14.81)$ & $5(20.00)$ & $14(4.00)$ & $2(15.38)$ & $16(13.68)$ \\
\hline \multirow[t]{2}{*}{ Thank You } & $0.01(0.10)$ & $1.18(0.76)$ & & Not referred & $53(98.15)$ & 25 & 25 & 13 & $116(99.15)$ \\
\hline & & & & Referred & $1(1.85)$ & 0 & 0 & 0 & $1(0.85)$ \\
\hline \multirow[t]{2}{*}{ Incentives $^{5}$} & $0.14(0.35)$ & $4.20(0.24)$ & & Not referred & $50(92.59)$ & $21(84.00)$ & $19(76.00)$ & $11(84.62)$ & $101(86.32)$ \\
\hline & & & & Referred & $4(7.41)$ & $4(16.00)$ & $6(24.00)$ & $\begin{array}{l}2(15.38) \\
\text { Grand Total }\end{array}$ & $\begin{array}{l}16(13.68) \\
n=277^{2}\end{array}$ \\
\hline
\end{tabular}




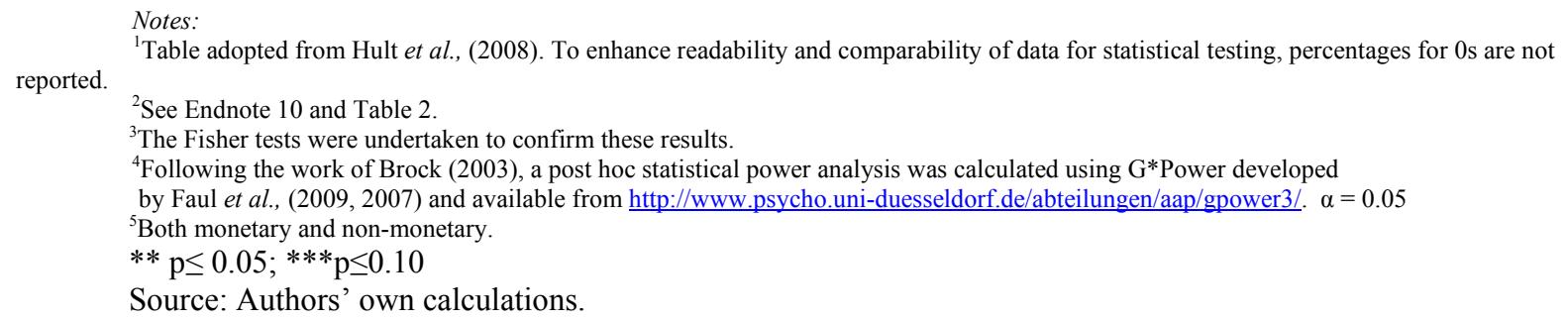

As shown in Table 5, amongst studies that surveyed one country, JIBS was the journal with the most studies (45 or 28\%), followed by IBR (43 or 27\%), and MIR (37 or 23\%). Out of one hundred and sixty studies that surveyed one country, seventy seven studies (48\%) referred to postal survey data collection procedures. MIR was the journal with most studies (21 or 27\%) that reported any techniques while JIBS was the journal with the least studies (16 or $21 \%$ ). Both IBR and JWB contained an equal number of studies (20 or $26 \%$ ) that referred to postal data collection methods. Further, it looks like the most common procedures utilized by authors that surveyed one country were follow-ups (41 or $26 \%$ ), and the least common techniques was a reminder (18 or 12\%). In addition, the findings indicate that statistically significant results were only found for reporting incentives $\left(\chi^{2}=8.09, \mathrm{p}=0.04\right)$ and reminders $\left(\chi^{2}=7.75, \mathrm{p}=0.05\right)$ amongst studies that surveyed one country across four journals. None of the studies that surveyed one country used a thank you letter as a postal data collection procedure.

As indicated in Table 5, amongst studies that surveyed more than one country, once again JIBS was the journal with the most studies (54 or $46 \%$ ). JIBS was followed equally by IBR and JWB (25 or $21 \%$ ), and MIR (13 or 11\%). Only thirty five studies (30\%), out of one hundred and seventeen studies that surveyed more than one country, referred to mail survey data techniques. In contrast to previous findings, JIBS was the journal with most studies (15 or 43\%) that reported any techniques while MIR was the journal with the least studies (14 or 12\%). Once again, Both IBR and JWB contained an equal number of studies ( 8 or $23 \%$ ) that referred to postal data collection methods. The findings suggest that the most frequent data collection procedures were incentives (16 or 14\%) and follow-ups (16 or 14\%), and the least used technique a pre-notice letter (7 or $6 \%)$. More, our findings point out that statistically significant result was only found for reporting a prenotice letter $\left(\chi^{2}=6.34, \mathrm{p}=0.10\right)$ as a data collection strategy amongst studies that surveyed more than one country across journals.

Neither studies that surveyed one country nor studies that surveyed more than one country were statistically significant for referring or not referring to mail survey administration techniques across journals. 


\section{Discussions and Implications of IB research}

The findings of this study in relation to "if" and "how" researchers in international business report the mail survey administration procedures are quite interesting. Our study shows that out of 285 studies examined across journals from 2000 to 2009, only 14 studies referred to Dillman's framework for postal data collection techniques. In addition, out of the remaining 271 studies, only 108 reported any of the data collection procedures proposed by Dillman $(1978,1999)$.

The findings demonstrate that within the 14 studies that referred to Dillman's work, only 6 studies mentioned his mail survey data collection procedures. The most often strategies used within those 14 studies were a covering letter, followed by a pre-notice letter and a follow-up, and a reminder. The journal that included the most studies that referred to Dillman's work was MIR. The three remaining journals included an equal amount of studies. The year in which the most studies were published, with reference to Dillman's work, was 2004.

In addition, the findings reveal that within the 108 studies that did not mention specifically Dillman's work but mentioned any survey data collection procedures, the most frequent procedures used were follow-ups, followed by incentives and a covering letter. The journal that included the largest amount of studies that mentioned any data collection techniques was JIBS followed by IBR and JWB. The years in which the most studies were published with any survey data collection techniques were from 2006 to 2009.

Our findings also show that follow-ups seemed to be the most common data collection procedure for mail survey amongst studies that surveyed one country, while follow-ups and incentives appeared to be the most frequent data collection technique between studies that surveyed more than one country.

Further, incentives and reminders seemed to be only statistically significant in studies that surveyed one country, while a pre-notice letter was found to be the only statistically significant procedure found in studies that surveyed more than one country.

What is more, none of the studies that surveyed one country reported the use of a thank you letter as a postal data collection method.

Without the establishment of data collection procedure equivalence, an issue recently pointed out by Hult et al., (2008), the reliability and validity of findings are called to question. To minimise those threats it is therefore essential to ensure comparable mail survey data collection procedures. While ensuring consistency in data collection methods may seem straightforward, cross-cultural differences might explain the variations (Craig and Douglas, 2000; Hult et al., 2008). However, those disparities could be overcome if, for example, researchers become more thorough in reporting and explaining how and why a particular strategy (or strategies) was used to gather data. 


\section{Conclusions}

In a period when IB researchers are confronted with a trend of increasing unwillingness of the general public to participate in the mail survey research, the success of postal surveys remains conditional upon following proper procedures for data collection and the implementation of proven strategies for stimulating response (e.g., Eichner and Habermehl, 1981; Cycota and Harris 2006; Baruch and Holtom, 2008).

The objective of this study was to investigate "if" and "how" researchers in IB report the mail survey administration procedures in order to seek or pin point the establishment of data collection procedure equivalence in cross-cultural research. Despite the usage of either ToDM or TaDM, we detected inadequate emphasis on data collection procedures in all IB journals between 2000 and 2009. The reasons for this are not clear, it is possible that we trust in good faith, that even if the equivalence of data collection procedures has not been stressed or pointed out in the papers, these are followed. However, we believe that considering the maturity of our field, a greater attention needs to be focused on reporting such procedures in order to be able to establish the equivalence of data collection procedures to ensure validity of our research.

We accept the fact that undertaking cross-culture comparative studies is not an easy task. However, we believe that in order to achieve comparable and generalizable results, a great attention should be paid by authors to reveal their strategies that were used for collecting a mail survey data in order to establish equivalence in postal survey data collection procedures. An issue that is becoming of a greater importance to the IB field (Herk et al., 2005; Sekaran 1983; Singh 1995). Although complete equivalence might probably never be possible, attempts have to be made to achieve equivalence.

The purpose of this work is not to criticize prior work but to recognize and bring to our attention the importance of an ongoing methodological debate in IB research. It is hoped to enhance researchers', editors' and reviewers' awareness of the importance of an adequate reporting of the survey administration procedures in order to develop a commonly understood IB vocabulary that allows the establishment of data collection procedures equivalence that is becoming increasing difficult.

\section{Acknowledgments:}

We are thankful for insightful comments received from all anonymous reviewers from the William Davidson Institute Working Papers Series as well as the $36^{\text {th }}$ Annual Meeting of the European Academy of International Business in Porto on early versions of this manuscript. Further, we would like to thank Nikolaos Papageorgiadis as well as all participants of the International Business Group seminar at the University of Uppsala for their valuable comments and suggestions on further development of this work. Finally, we are indebted to Michael-Jörg Oesterle and his editorial assistant, Julia Vongerichten, for supplying us with hard copies of MIR's Special and Focus Issues. Any remaining errors are ours. 


\section{Endnote:}

${ }^{1}$ According to Pike (1966) the terms "emic" and "etic" stem from a linguistic distinction between phonemics and phonetics.

${ }^{2}$ Please refer to Cavusgil and Das (1997) for more detailed explanation of the model.

${ }^{3}$ Dillman's framework can also be used for collecting a primary data via an electronic survey (Dillman, 1999, 2000).

${ }^{4}$ For other potential sources of bias in research project refer, for example, to Cox (1974) or Cavusgil and Das (1997).

${ }^{5}$ For other details of the ToDM and how they are integrated to make a holistic effect please see Dillman (1978).

${ }^{6}$ Or seven weeks after the first questionnaire was sent out.

${ }^{7}$ For more detail please see Dillman (2000).

${ }^{8}$ At the time of data collection, none of the special and focus issues were available electronically.

${ }^{9}$ This data is not present in Table 2 but can be available from the corresponding author.

${ }^{10}$ Excluding 8 studies for which it was not clear how many countries were surveyed. See Table 2 for sample characteristics

\section{References:}

Adler, N.J. (1983a). Cross-cultural management research: the ostrich and the trend, Academy of Management Review, 2, 226-232.

Baruch, Y., and Holtom, B.C. (2008). Survey response rate levels and trends in organizational research. Human Relation, 61(8), 1139-1160.

Berry, J.M., and Dasen, P. (1974). Introduction to Culture and Cognition. London: Methuen.

Berry, J.M. (1999). On cross-cultural comparability. International Journal of Psychology, 4(2), 119-128.

Blau, P.M., (1964). Exchange and power in social life. New York: Wiley.

Brennan, R.D. (1958). Trading stamps as an incentive in mail surveys. Journal of Marketing, 22, 306-317

Brock, J, K-W. (2003). The 'power' of international business research. Journal of International Business Studies, 34(1), 90-99.

Boyd, B.K., Gove, S., and Hitt, M. (005) Construct Measurement in Strategic Management Research: Illusion or Reality? Strategic Management Journal, 6, 239-257.

Coviello, N.E., and Johns, M.V. (2004). Methodological issues in international entrepreneurship research, Journal of Business Venturing, 19, 485-508.

Cox, E.P. (1974). Research for Business Decisions: An Interdisciplinary Approach. Bureau of Business Research, The University of Texas. Austin.

Craig, C.S., and Douglas, S.P. (2000). International Marketing Research (2 ${ }^{\text {nd }}$ ed). New York: Wiley $\&$ Sons.

Coudounaris, D., Kvasova, O., Leonidou, L.C, Pitt, L.F., and Nel, D. (2009). Fifteen Good Years. An Analysis of Publications in Management International Review. Management International Review, 49(5), 671-684.

Cycota, C.S., and Harris, D.A. (2006). What (Not) to Expect When Surveying Executives: A MetaAnalysis of Top Managers Response Rates and Techniques Over Time. Organizational Research Methods, 9(2), 133-160.

De Leeuw, E.D., and Hox, J.J. (1988). The Effects of Response-Stimulating Factors on Response Rates and Data Quality in Mail Surveys: A Test of Dillman's Total Design Method. Journal of Official Statistics, 4(3), 241-249.

Dillman, D.A., Christenson, J.A., Carpenter, E.H., and Brooks, R. (1974). Increasing mail questionnaire response: A four-state comparison. American Sociological Review, 39, 744-756.

Dillman, D.A., and Sangster, R.L. (1990). Mail Surveys: A Comprehensive Bibliography 19741989, Technical Report, Pullman: Washington State University.

Dillman, D.A. (2000). Mail and Internet Surveys. The Tailored Design Method. (2 ${ }^{\text {nd }}$ ed). New York: Wiley \& Sons. 
Dillman, D. A. (1999). Mail and other self-administered surveys in the $21^{\text {st }}$ century: The beginning of a new era. The Gallup Research Journal, Winter/Spring, 121-140.

Dillman, D.A. (1991). The Design and Administration of Mail Surveys. Annual Review of Sociology, 17, 225-249.

Dillman, D.A. (1978). Mail and Telephone Surveys: The Total Design Method. New York: Wiley \& Sons.

Dillman, D. A. (1972). Increasing mail questionnaire response for larger samples of general public. Public Opinion Quarterly, 35(3), 254-257.

DuBois, F.L., and Reeb, D.M . (2000) Ranking the International Business Journals. Journal of International Business Studies, 31 (4), 689-704.

Eichner., K., and Habermehl, W. (1981). Predicting Response Rates in Mail Questionnaires. Aerican Sociological Review, 46(3), 361-363.

Faul, F., Erdfelder, E., Buchner, A., and Lang, A.-G. (2009). Statistical power analyses using G*Power 3.1: Tests for correlation and regression analyses. Behavior Research Methods, 41, 1149-1160.

Faul, F., Erdfelder, E., Lang, A.-G., \& Buchner, A. (2007). G*Power 3: A flexible statistical power analysis program for the social, behavioural, and biomedical sciences. Behavior Research Methods, 39, 175-191.

Goyder, J.C. (1982) Further Evidence on Factors Affecting Response Rates to Mailed Questionnaires. American Sociological Review, 47, 550-553.

Ghauri, P.N., and Gronhaug, K. (2010) Research Methods in Business Studies. A Practical Guide. $\left(3^{\text {rd }}\right.$ ed.), Harlow: Pearson Education Ltd.

Greatz, B. (1985). The potential of mail surveys. Australian and New Zealand Journal of Sociology, $21,445-455$.

Green, R.T., and White, P.D. (1976) Methodological Considerations in Cross-national Consumer Research, Journal of International Business Studies. 14, 81-87.

Groves, R.M. (2004). Survey errors and survey costs. New Jersey: Wiley and Sons Inc.

Groves, R.M. (1989). Research on survey data quality. Public Opinion Quarterly, 51, 156-172.

Harris, S.(2000) Reconciling positive and interpretative international management research: a

native category approach. International Business Review, 9, 755-770.

Harzing, A-W, (1997). Response Rates in International Mail Surveys: Results of a 22-Country Study. International Business Review, 6(6), 641-665.

Herk, H., Poortinga, Y.H., and Verhallen, T.M.M. (2005). Equivalence of survey data: relevance for international marketing. European Journal of Marketing, 39(3/4), 351-364.

Herberlein, T.A., and Baumgartner, R. (1978). Factors affecting response rates to mailed questionnaires: A quantitative analysis of the published literature. American Sociological Review, 43, 447-462.

Hofstede, G. (1980) Culture's Consequences: International Differences in Work-Related Values. Beverly Hills: Sage.

Homans, C.G. (1973). Social Behaviour. London: Routledge and Kegan.

Hult, G.T.M., Ketchen, D.J., Griffith, D.A., Finnegen, C.A., Gonzales-Padron, T., Harmancioglu, N., Huang, Y., Talay, M.B., and Cavusgil, S.T. (2008). Data equivalence in cross-cultural international business research: assessment and guidelines. Journal of International Business Studies, 39(6), 1027-1044.

Jobber, D., Mirza, H., and Wee, K.H. (1991). Incentives and response rates to cross-national business surveys: a logit model analysis. Journal of International Business Studies, 22(4), 711 721.

Jobber, D., and Saunders, J. (1988). An experimental investigation into cross-national business survey response rate. Journal of International Business Studies, 19(3), 483 - 489.

Jussaume, R.A., and Yamada, Y. (1990). A Comparison of the Variability of Mail Surveys in Japan and the United States. Public Opinion Quarterly, 54(2), 219-228. 
Kjeldgaard, D., Csaba. F., and Ger, G. (2006). Grasping the global: multi-sited ethnographic market studies. In Belk, R. W. (ed), Handbook of Qualitative Research Methods in Marketing, Edward Elgar Publishing, 521-534.

Krippendorf, K. (2004) Content Analysis: An Introduction to its Methodology, $2^{\text {nd }}$ ed., Thousand Oaks, California: Sage Publications

Ladd, E.C. (1980). Polling and the press: the clash of institutional imperatives. Public Opinion Quarterly, 44, 574-84.

Linsky, A.S. (1975). Stimulating responses to mailed questionnaire: A review. Public Opinion Quarterly, 39, 82-101.

Mullen, M.R. (1995). Diagnosing measurement equivalence in cross-national research. Journal of International Business Studies, 26(3), 573-596.

Nasif, E.G., Al-Daeaj, H., Ebrahim, B., Thibodeaux, M.S. (1991) Methodology Problems in CrossCultural Research : An Updated Review, Management International Review. 31, 79-91.

Nederhof, A.J. (2002). The content analysis guidebook. Thousand Oaks, CA: Sage

Nederhof, A.J. (1983). The effects of material incentives in mail surveys: Two studies, Public Opinion Quarterly, 47/1, 102-111.

Peng, T.K., Peterson, M.F., and Shyi, Y-P. (1991). Quantitative Methods in Cross-National Management Research: Trends and Equivalence Issues. Journal of Organizational Behaviour, 12(2), 87-107.

Piekkari, R., Welch, C., and Paavilainen, E. (2009). The Case Study as Disciplinary Convention: Evidence from International Business Journals. Organisational Research Methods, 12(3), 567589.

Pike, K. (1966). Language in Relation to a United Theory of the Structure of Human Behaviour, Mouton:The Hague.

Platt, J. (1996). A history of sociological research methods in America 1920-1960. Cambridge, UK: Cambridge University Press.

Rada, V.D. (2000). Mail Surveys Using Dillman's TDM in a Southern European Country: Spain. International Journal of Public Opinion Research, 13(2), 159-172.

Reynolds, N.L., Simintiras, A.C., and Diamantopoulos, A. (2003). Theoretical justifications of sampling choices in international marketing research: key issues and guidelines for research. Journal of International Business Studies, 34(1), 80-89.

Samiee, S., and Jeong. I. (1994). Cross-Cultural Research in Advertising: An Assessment of Methododlogies. Journal of the Academy of Marketing Science, 22(2), 205-217.

Schaffer, B.S., and Riordan, C.M. (2003). A review of cross-cultural methodologies for organizational research: a best -practices approach. Organizational , 6(2), 169-215. Research Methods

Sekaran, U. (1983). Methodological and theoretical issues and advancements in cross-national research. Journal of International Business Studies, 2, 61-74.

Singh, J. (1995). Measurement issues in cross-national research. Journal of International Business Studies, 14(2), 61-73.

Scot, C. (1961). Research on mail surveys. Journal of the Royal Statistical Society, 124, 143-205.

Yaprak, A. (2006). Measurement problems in cross-national consumer research: the state-of-the-art and future research directions. In S.C. Jain (ed), Handbook of research in international marketing, Cheltenham: Edward Elgar, 174-190.

Yang, Z., Wang, X., and $\mathrm{Su}, \mathrm{Ch}$. (2006). A review of research methodologies in international business, International Business Studies, 15(6), 601-617

Watson, J.J. (1965). Improving the response rate in mail research. Journal of Advertising Research, $5,48-50$.

Weber, R. P. (1990). Basic Content Analysis, 2nd ed. Newbury Park, CA.

Weisberg, H.F. (2005). The total survey error approach: a guide to the new science of survey research. Chicago: The University of Chicago Press $\backslash$ 


\section{DAVIDSON INSTITUTE WORKING PAPER SERIES - Most Recent Papers}

The entire Working Paper Series may be downloaded free of charge at: www.wdi.umich.edu

CURRENT AS OF $3 / 17 / 11$

\begin{tabular}{|c|c|c|}
\hline Publication & Authors & Date \\
\hline $\begin{array}{l}\text { No. 1013: Establishing Data Collection Procedures Equivalence in } \\
\text { International Business Research }\end{array}$ & $\begin{array}{l}\text { Agnieszka Chidlow \& } \\
\text { Pervez N. Ghauri }\end{array}$ & $\begin{array}{l}\text { March } \\
2011 \\
\end{array}$ \\
\hline $\begin{array}{l}\text { No. 1012: The Link between Innovation and Productivity in Estonia's } \\
\text { Service Sectors }\end{array}$ & Priit Vahter \& Jaan Masso & $\begin{array}{l}\text { March } \\
2011\end{array}$ \\
\hline $\begin{array}{l}\text { No. 1011: Learning by exporting: evidence based on data of knowledge } \\
\text { flows from innovation surveys in Estonia }\end{array}$ & Priit Vahter & Feb 2011 \\
\hline $\begin{array}{l}\text { No. 1010: Firm Investment \& Credit Constraints in India, } 1997 \text { - 2006: } \\
\text { A stochastic frontier approach }\end{array}$ & $\begin{array}{l}\text { Sumon Bhaumik, Pranab Kumar } \\
\text { Das and Subal C. Kumbhakar }\end{array}$ & Jan 2011 \\
\hline No. 1009: Industrial Enlargement And Competitiveness Index & Art Kovacic & Jan 2011 \\
\hline $\begin{array}{l}\text { NO. 1008: SUPPORTING AFRICA'S POST-CRISIS GROWTH: THE ROLE OF } \\
\text { MACROECONOMIC POLICIES }\end{array}$ & $\begin{array}{l}\text { Zuzana Brixiova, Leonce } \\
\text { Ndikumana \& Kaouther } \\
\text { Abderrahim }\end{array}$ & Jan 2011 \\
\hline $\begin{array}{l}\text { No. 1007: The Funding \& Efficiency of Higher Education in Croatia \& } \\
\text { Slovenia: A Non-Parametric Comparison w/ the EU \& OECD Countries. }\end{array}$ & $\begin{array}{l}\text { Aleksander Aristovnik and } \\
\text { Alka Obadic }\end{array}$ & Jan 2011 \\
\hline $\begin{array}{l}\text { No. 1006: Public Investment and Fiscal Performance in New EU } \\
\text { Member States }\end{array}$ & Jan Hanousek and Evžen Kočenda & Dec 2010 \\
\hline No. 1005: Is Monetary Policy in New Member States Asymmetric? & Bořek Vašíček & Dec. 2010 \\
\hline $\begin{array}{l}\text { No. 1004: Inflation Targeting in Brazil, Chile \& South Africa: An } \\
\text { Empirical Investigation of Their Monetary Policy Framework }\end{array}$ & Mona Kamal & Nov. 2010 \\
\hline $\begin{array}{l}\text { No. 1003: Assessing Mondragon: Stability and Managed Change in the } \\
\text { Face of Globalization }\end{array}$ & $\begin{array}{l}\text { Saioa Arando, Fred Freundlich, } \\
\text { Monica Gago, Derek C. Jones } \\
\text { and Takao Kato }\end{array}$ & Nov. 2010 \\
\hline $\begin{array}{l}\text { No. 1002: Money Market Integration and Sovereign CDS Spreads } \\
\text { Dynamics in the New EU States }\end{array}$ & $\begin{array}{l}\text { Peter Chobanov, Amine Lahiani } \\
\text { and Nikolay Nenovsky }\end{array}$ & Oct 2010 \\
\hline No. 1001: Modeling transition in Central Asia: the Case of Kazakhstan & $\begin{array}{l}\text { Gilles DUFRENOT, Adelya } \\
\text { OSPANOVA, Alain SAND- } \\
\text { Zantman }\end{array}$ & Oct 2010 \\
\hline $\begin{array}{l}\text { No.1000: Unlocking Productive Entrepreneurship in Ethiopia: } \\
\text { Which Incentives Matter? }\end{array}$ & $\begin{array}{l}\text { Zuzana Brixiova \& } \\
\text { Emerta Asaminew }\end{array}$ & Oct 2010 \\
\hline No.999: Price convergence and market integration in Russia & Konstantin Gluschenko & Sept 2010 \\
\hline $\begin{array}{l}\text { No. 998: Bank Efficiency in Transitional Countries: Sensitivity to } \\
\text { Stochastic Frontier Design }\end{array}$ & Zuzana Irsova & Sept 2010 \\
\hline $\begin{array}{l}\text { No. 997: EU Enlargement and Monetary Regimes from the Insurance } \\
\text { Model Perspectives }\end{array}$ & Nikolay Nenovsky & June 2010 \\
\hline $\begin{array}{l}\text { No. 996: Which Foreigners are Worth Wooing? } \\
\text { A Meta-Analysis of Vertical Spillovers from FDI }\end{array}$ & $\begin{array}{c}\text { Tomas Havranek and } \\
\text { Zuzana Irsova }\end{array}$ & June 2010 \\
\hline $\begin{array}{l}\text { No. 995: Environmental Regulation and Competitiveness: } \\
\text { Evidence from Romania }\end{array}$ & $\begin{array}{c}\text { Guglielmo M. Caporale, } \\
\text { Christophe Rault, Robert Sova \& } \\
\text { Anamaria Sova }\end{array}$ & June 2010 \\
\hline $\begin{array}{l}\text { No. 994: Pollution Abatement And Control Expenditure In Romania: } \\
\text { A Multilevel Analysis }\end{array}$ & $\begin{array}{c}\text { Guglielmo M. Caporale, } \\
\text { Christophe Rault, Robert Sova \& } \\
\text { Anamaria Sova }\end{array}$ & June 2010 \\
\hline $\begin{array}{l}\text { No. 993: Do Innovative Workplace Practices Foster Mutual Gains? } \\
\text { Evidence From Croatia }\end{array}$ & Derek Jones and Srecko Goic & May 2010 \\
\hline $\begin{array}{l}\text { No. 992: Firm And Employee Effects Of An Enterprise Information } \\
\text { System: Micro-Econometric Evidence }\end{array}$ & $\begin{array}{l}\text { Derek Jones, Panu Kalmi } \\
\text { and Antti Kauhanen }\end{array}$ & June 2010 \\
\hline
\end{tabular}

